\title{
Distribution of Various Maxilla-Mandibular Positions and Cephalometric Comparison in Chinese Skeletal Class II Malocclusions
}

\author{
Xin Xiong ${ }^{1}$, Yanmei Huang ${ }^{2}$, Wei Liu ${ }^{3}$, Yange $\mathrm{Wu}^{4}$, Yating $\mathrm{Yi}^{5}$, Jun Wang ${ }^{6}$
}

\begin{abstract}
Aim: To obtain the distribution of different maxilla-mandibular characteristics in Chinese skeletal class II mixed dentition patients and to compare the differences of cephalometric variables among different maxilla-mandibular types.

Materials and methods: A cross-sectional study was conducted among 310 skeletal class II patients in mixed dentition. The patients were divided into 6 groups according to SNA and SNB angle of the cephalogram. A total of 38 cephalometric measurements were measured on their cephalograms. Differences among groups were tested by one-way analysis of variance.

Results: There were 34 (10.97\%) patients in group I, 10 (3.23\%) in group II, 4(1.29\%) in group III, 69 (22.26\%) in group IV, 133 (42.90\%) in group $\mathrm{V}$, and 60 (19.35\%) in group VI. In all, 14.19\% of the patients exhibited maxillary protrusion (MxP), and 62.26\% exhibited mandibular retrusion $(\mathrm{MnR})$ with either normal or retruded maxilla. Groups II and III were excluded for statistical comparison due to a limited sample size. Statistical differences were found in 25 cephalometric measurements among the other 4 groups. Patients with MnR (groups V and VI) exhibited bigger sella angle, gonial angle, Frankfort mandibular plane angle, and smaller mandibular body length and ramus height than patients without MnR ( $p$ value $<0.05$ )

Conclusion: The most common etiology forming skeletal class II malocclusion in Chinese children was MnR, which was mainly caused by the small size and hyperdivergent growth direction of mandible.

Clinical significance: The study presents various cephalometric characteristics of Chinese skeletal class II malocclusions. The results indicated that for the early orthodontic treatment of Chinese class II children with mixed dentition, orthodontists might emphasize more importance to mandibular length augmentation and growth direction change in mandible.
\end{abstract}

Keywords: Cephalometrics, Craniomaxillofacial characteristics, Growth evaluation, Mixed dentition, Skeletal class II.

The Journal of Contemporary Dental Practice (2020): 10.5005/jp-journals-10024-2897

\section{INTRODUCTION}

Skeletal class II malocclusion is a common type of discrepancy in children with mixed dentition. As a sagittal discrepancy problem, it has different discrepancy mechanisms based on the anteroposterior position of maxilla and mandible. There are six types: maxilla protrusion with normal mandible ( $\mathrm{MxP}$ and $\mathrm{MnN})$, maxilla protrusion with protruded mandible ( $\mathrm{MxP}$ and $\mathrm{MnP}$ ), maxilla protrusion with retruded mandible ( $M x P$ and $M n R$ ), normal maxilla and mandible ( $\mathrm{MxN}$ and $\mathrm{MnN})$, normal maxilla with retruded mandible ( $\mathrm{MxN}$ and $\mathrm{MnR}$ ), and retruded maxilla and mandible (MxR and MnR). ${ }^{1}$

Children with mixed dentition have relatively more growth potential. ${ }^{2}$ Better use of the growth potential could achieve more effective and stable outcomes. In Chinese children with mixed dentition seeking for orthopedic treatment, the most common malocclusion is the skeletal class II malocclusion. ${ }^{3}$ The correction of skeletal class II malocclusion includes both skeletal and dental effect. The ideal treatment effect that the orthodontists expect is skeletal effect such as mandibular length augmentation and condyle growth. ${ }^{4}$ Application of functional appliances (FAs), especially during the pubertal growth phase, could bring an extent of skeletal effect and dental effect, ${ }^{5,6}$ but unavoidably, and some side effects. The side effects of FAs include increase of occlusal plane and gonial angle (Ar-Go-Me), proclination of lower incisors, and retroclination of upper incisors. ${ }^{7,8}$ There are about 10 different ${ }^{1-6}$ Department of Orthodontics, State Key Laboratory of Oral Disease,
National Clinical Research Center for Oral Disease, West China Hospital of Stomatology, Sichuan University, Chengdu, China

Corresponding Author: Jun Wang, Department of Orthodontics, State Key Laboratory of Oral Disease, National Clinical Research Center for Oral Disease, West China Hospital of Stomatology, Sichuan University, Chengdu, China, Phone: +86 0288550 1425, e-mail: wangjunv@scu. edu.cn

How to cite this article: Xiong X, Huang Y, Liu W, et al. Distribution of Various Maxilla-Mandibular Positions and Cephalometric Comparison in Chinese Skeletal Class II Malocclusions. J Contemp Dent Pract 2020;21(8):822-828.

Source of support: This research was supported by the National Natural Science Foundation of China to Jun Wang (No. 81771114 and No. 81970967).

Conflict of interest: None

FAs and their modified devices, ${ }^{9}$ and the treatment effects and side effects vary with different appliances. Different types of patients should be treated with appropriate approaches in order to get more skeletal effects and fewer side effects. Accurate analysis of facial types and discrepancy etiology is very important for the treatment plan.

(0) The Author(s). 2020 Open Access This article is distributed under the terms of the Creative Commons Attribution 4.0 International License (https://creativecommons. org/licenses/by-nc/4.0/), which permits unrestricted use, distribution, and non-commercial reproduction in any medium, provided you give appropriate credit to the original author(s) and the source, provide a link to the Creative Commons license, and indicate if changes were made. The Creative Commons Public Domain Dedication waiver (http://creativecommons.org/publicdomain/zero/1.0/) applies to the data made available in this article, unless otherwise stated. 
For the analysis of facial types and discrepancy mechanisms, cephalogram is the mainly used approach. ${ }^{10}$ The proportion varies in different racial and ethnic groups. Cephalometric studies showed $27 \%$ of dental class II patients had mandibular retrusion, and $57.3 \%$ of the patients had maxillary protrusion $(\mathrm{MxP}){ }^{11}$ However, Pancherz reported that $\sim 48$ to $49 \%$ of Caucasian skeletal class II children at the age of 8 to 10 years had mandible retrusion $(\mathrm{MnR}) .^{12}$ The proportion varies in different racial and ethnic groups. The Mongoloid population, such as Chinese, Korean, Japanese, are apt to develop backward rotated mandible. ${ }^{13,14}$ In all, $12.9 \%$ of Chinese adult skeletal class II patients exhibited MxP and $60.8 \%$ exhibited MnR. ${ }^{15}$ For Chinese skeletal class II patients, with relatively more common MnR and smaller mandible, the treatment priority should be different. Therefore, for Chinese skeletal class II children, the application of FAs might be more important. However, the distribution of different types in Chinese skeletal class II patients with mixed dentition have not been explored. Analysis of the proportion and relevant etiology will help to understand the formation of skeletal class II malocclusion and determine the focus of follow-up research.

Thus, the aims of this study were to analyze the distribution of different maxilla-mandibular characteristics in Chinese skeletal class II mixed dentition patients and to compare the differences of cephalometric variables among different maxilla-mandibular types.

\section{Materials and Methods}

\section{Subjects}

This retrospective study was carried out at department of orthodontics, West China Hospital of Stomatology. The study protocol was approved by the Institutional Review Board of our Hospital (Approval no.WCHSIRB-D-2019-203). Both the patients seeking for treatment and their parents were informed about the possibility that the patients' records might be used for teaching and research purposes, and informed consent was obtained. A total of 310 patients were included in this study.

In this study, patients' medical records, panoramic radiograph, and cephalograms were selected from the database of our hospital and anonymized for analysis. The norms of ANB, SNA, and SNB angle were derived from the database of our hospital. ${ }^{16}$

A total of 872 patients were screened. The inclusion criteria were as follows: (1) Chinese children between the age of 6 and 12 with dentition containing primary and permanent teeth; (2) patients registered in West China Hospital of Stomatology from May 2018 to August 2019; (3) the ANB angle of pretreatment cephalogram was more than $5^{\circ},{ }_{i}^{16}(4)$ panoramic radiograph showed the permanent dentition was normally developed, without missing teeth or supernumerary teeth, and the tooth germs were taken into account as well; (5) intraoral examination showed no signs of abnormal tooth morphology such as peg-shaped teeth and fused teeth; and (6) pretreatment records with high-quality cephalograms.

Patients who manifested craniofacial syndromes, clefts, trauma, deformity secondary to systematic disease, and had orthodontic or orthognathic treatment before were excluded. After screening, 310 patients were included; subsequently cephalometric analysis and statistical analysis were performed.

\section{Cephalometry}

All the cephalograms were taken at the Department of Radiology in our Hospital according to standardized cephalometric radiographic procedures with natural head position and with teeth in centric occlusion. ${ }^{17}$

The lateral cephalograms were obtained during the first visit, after which they were digitalized and analyzed (Uceph, version 780, Chengdu, China) by independent observers.

The patients were divided into six groups according to SNA and SNB angle of the cephalogram: ${ }^{16}$

Group I $(n=34)$ : $\mathrm{MxP}$ and $\mathrm{MnN}, \mathrm{SNA}>85^{\circ}, 82^{\circ} \geq \mathrm{SNB} \geq 76^{\circ}$;

Group II $(n=10)$ : MxP and MnP, SNA $>85^{\circ}, \mathrm{SNB}>82^{\circ}$;

Group III $(n=4)$ : $\mathrm{MxP}$ and MnR, SNA $>85^{\circ}, \mathrm{SNB}<76^{\circ}$;

Group IV ( $n=69)$ : $\mathrm{MxN}$ and $\mathrm{MnN}, 85^{\circ} \geq \mathrm{SNA} \geq 79^{\circ}, 82^{\circ} \geq \mathrm{SNB}$ $\geq 76^{\circ}$;

Group V ( $n=133)$ : $\mathrm{MxN}$ and $\mathrm{MnR}, 85^{\circ} \geq \mathrm{SNA} \geq 79^{\circ}, \mathrm{SNB}<76^{\circ}$; and Group VI $(n=60)$ : MxR and MnR, $79^{\circ}>$ SNA, SNB $<76^{\circ}$.

The cephalometric reference plane was the Frankfort horizontal (FH) plane. The definitions of landmarks and measurements are presented in Table 1 and Figure 1. There were 35 measurements, classified into five categories (Table 2):

Table 1: Cephalometric landmarks and measurements definitions

\begin{tabular}{|c|c|}
\hline Landmark & Definition \\
\hline Orbitale (Or) & $\begin{array}{l}\text { The lowest point on the average of the } \\
\text { right and left borders of the bony orbit }\end{array}$ \\
\hline Porion (P) & $\begin{array}{l}\text { The midpoint of the line connecting the } \\
\text { most superior point of the radiopacity } \\
\text { generated by each of the two ear rods }\end{array}$ \\
\hline Sella (S) & The center of sella turcica \\
\hline Nasion (N) & $\begin{array}{l}\text { The most anterior point of the frontonasal } \\
\text { suture }\end{array}$ \\
\hline Articulare (Ar) & $\begin{array}{l}\text { Intersection of the lateral radiographic } \\
\text { image of the posterior border of the ramus } \\
\text { with the base of the occipital bone }\end{array}$ \\
\hline Go (Gonion) & $\begin{array}{l}\text { Midpoint of the angle of the mandible, } \\
\text { found by bisecting the angle formed by } \\
\text { the mandibular plane and a plane through } \\
\text { articulare, posterior and along the portion } \\
\text { of the mandibular ramus inferior to it }\end{array}$ \\
\hline $\begin{array}{l}\text { Anterior nasal spine } \\
\text { (ANS) }\end{array}$ & $\begin{array}{l}\text { Sharp median process formed by the } \\
\text { forward prolongation of the two maxil- } \\
\text { lae at the lower margin of the anterior } \\
\text { aperture of the nose }\end{array}$ \\
\hline $\begin{array}{l}\text { Posterior nasal spine } \\
\text { (PNS) }\end{array}$ & $\begin{array}{l}\text { The most posterior point at the sagittal } \\
\text { plane on the bony hard palate }\end{array}$ \\
\hline Pogonion (Pog) & The most anterior point on the chin \\
\hline Menton (Me) & $\begin{array}{l}\text { The most inferior point on the mandibular } \\
\text { symphysis in the midline }\end{array}$ \\
\hline Gnathion (Gn) & $\begin{array}{l}\text { The lowest, most anterior midline point on } \\
\text { the symphysis of the mandible }\end{array}$ \\
\hline $\begin{array}{l}\text { Upper first molar } \\
\text { (UMT) }\end{array}$ & Maxillary first molar mesial cusp \\
\hline $\begin{array}{l}\text { Upper incisor incisal, } \\
\text { Edge (UIE) }\end{array}$ & $\begin{array}{l}\text { The incisal tip of the maxillary central } \\
\text { incisor }\end{array}$ \\
\hline Lower first molar (LMT) & Mandibular first molar mesial cusp \\
\hline $\begin{array}{l}\text { Lower incisor incisal, } \\
\text { Edge (LIE) }\end{array}$ & $\begin{array}{l}\text { The incisal tip of the mandibular central } \\
\text { incisor }\end{array}$ \\
\hline Soft tissue nasion $\left(\mathrm{N}^{\prime}\right)$ & $\begin{array}{l}\text { Intersection of the anterior cranial base } \\
\text { plane and the forehead soft tissue border }\end{array}$ \\
\hline $\begin{array}{l}\text { Soft tissue pogonion } \\
\text { (Pog') }\end{array}$ & $\begin{array}{l}\text { The most anterior point on the chin in the } \\
\text { midsagittal plane }\end{array}$ \\
\hline
\end{tabular}




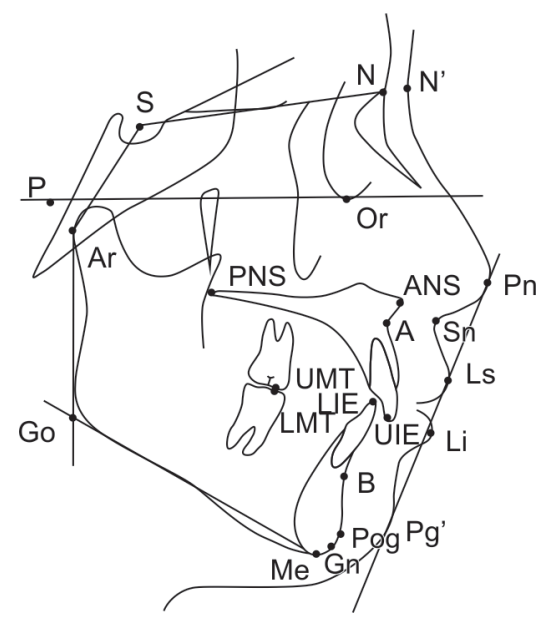

Fig. 1: The cephalometric landmarks used in this study
Cranial measurements: sella angle $\left(\mathrm{N}-\mathrm{S}-\mathrm{Ar},{ }^{\circ}\right)$, articular angle (S-Ar-Go, $\left.{ }^{\circ}\right), \mathrm{S}-\mathrm{N}(\mathrm{mm})$, and S-Ar (mm).

Maxillary, mandibular, and maxillomandibular skeletal measurements: gonial angle $\left({ }^{\circ}\right)$, upper gonial angle $\left({ }^{\circ}\right)$, lower gonial angle $\left({ }^{\circ}\right)$, PP-FH $\left({ }^{\circ}\right)$, PP-MP $\left({ }^{\circ}\right)$, FH-NPo (Facial Angle) $\left({ }^{\circ}\right)$, mandibular body length $(\mathrm{mm})$, ramus height $(\mathrm{mm})$, A-N Perp distance $(\mathrm{mm})$, Pog-N Perp distance $(\mathrm{mm})$, and S-N/Go-Me (\%).

Vertical relationship measurements: $\mathrm{SN}-\mathrm{MP}\left({ }^{\circ}\right), \mathrm{FMA}\left({ }^{\circ}\right)$, anterior facial height $(\mathrm{mm})$, upper anterior facial height (N-ANS, $\mathrm{mm}$ ), lower anterior facial height (ANS-Me, $\mathrm{mm}$ ), posterior facial height (S-Go, $\mathrm{mm})$, and facial height index (\%).

Dental measurements: IMPA $\left({ }^{\circ}\right)$, FMIA $\left({ }^{\circ}\right)$, U1-SN $\left({ }^{\circ}\right)$, U1-L1 (interincisal angle, $\left.{ }^{\circ}\right) \mathrm{SN}-\mathrm{OP}\left({ }^{\circ}\right), \mathrm{MP}-\mathrm{OP}\left({ }^{\circ}\right), \mathrm{U} 6-\mathrm{PP}(\mathrm{mm})$, and L6-MP (mm).

Soft tissue measurements: nasolabial angle $\left({ }^{\circ}\right)$, soft tissue facial angle $\left(\mathrm{FH}-\mathrm{N}^{\prime} \mathrm{Pg}^{\prime},{ }^{\circ}\right)$, facial convexity angle $\left(\mathrm{N}^{\prime}-\mathrm{Sn}-\mathrm{Pg}^{\prime},{ }^{\circ}\right), \mathrm{UL}-\mathrm{EP}(\mathrm{mm})$, and LL-EP (mm).

Table 2: Comparison of cephalometric measurements of groups I, IV, V, and group VI ( $x \pm s$ )

\begin{tabular}{|c|c|c|c|c|c|}
\hline Measurements & $G I(n=34)$ & $G I V(n=69)$ & $G V(n=133)$ & $G V I(n=60)$ & $p$ \\
\hline \multicolumn{6}{|l|}{ Cranial measurements } \\
\hline $\mathrm{N}-\mathrm{S}-\operatorname{Ar}\left({ }^{\circ}\right)$ & $119.197 \pm 4.8716$ & $121.620 \pm 4.3181$ & $125.088 \pm 3.8672$ & $128.417 \pm 4.3790$ & $0.000 * * *$ \\
\hline S-Ar-Go $\left(^{\circ}\right)$ & $152.547 \pm 5.3424$ & $150.874 \pm 14.7090$ & $150.358 \pm 5.2182$ & $148.902 \pm 5.6986$ & 0.240 \\
\hline $\mathrm{S}-\mathrm{N}(\mathrm{mm})$ & $59.162 \pm 3.7201$ & $60.174 \pm 4.5391$ & $60.980 \pm 4.8464$ & $59.948 \pm 4.3521$ & 0.147 \\
\hline $\mathrm{S}-\operatorname{Ar}(\mathrm{mm})$ & $30.788 \pm 2.5506$ & $31.235 \pm 3.3530$ & $31.089 \pm 3.7132$ & $29.498 \pm 3.3808$ & $0.016^{*}$ \\
\hline \multicolumn{6}{|c|}{ Maxillary, mandibular and maxillomandibular skeletal measurements } \\
\hline Gonial angle $\left(^{\circ}\right)$ & $121.626 \pm 6.2711$ & $120.355 \pm 5.8506$ & $122.258 \pm 6.0081$ & $124.828 \pm 7.0089$ & $0.001^{* *}$ \\
\hline Upper gonial angle $\left(^{\circ}\right)$ & $46.974 \pm 3.3377$ & $48.103 \pm 15.2105$ & $46.858 \pm 3.3924$ & $46.857 \pm 3.5293$ & 0.735 \\
\hline Lower gonial angle $\left({ }^{\circ}\right)$ & $74.641 \pm 4.8512$ & $74.230 \pm 4.3721$ & $75.401 \pm 4.4315$ & $77.973 \pm 5.8076$ & $0.000^{* * *}$ \\
\hline $\mathrm{PP}-\mathrm{FH}\left({ }^{\circ}\right)$ & $0.335 \pm 3.3737$ & $0.061 \pm 3.2640$ & $0.310 \pm 3.5715$ & $-0.963 \pm 3.1914$ & 0.102 \\
\hline PP-MP $\left({ }^{\circ}\right)$ & $26.432 \pm 5.0115$ & $27.001 \pm 5.2106$ & $28.411 \pm 5.0399$ & $31.828 \pm 5.9304$ & $0.000 * * *$ \\
\hline FH-NPo (Facial Angle) $\left(^{\circ}\right)$ & $85.918 \pm 3.3186$ & $84.400 \pm 2.2479$ & $82.903 \pm 2.8125$ & $82.088 \pm 2.3452$ & $0.000^{* * *}$ \\
\hline Mandibular body length (mm) & $60.959 \pm 4.2724$ & $62.054 \pm 5.4837$ & $60.549 \pm 5.1136$ & $58.233 \pm 5.2490$ & $0.001^{* *}$ \\
\hline Ramus height (mm) & $39.518 \pm 3.1176$ & $39.033 \pm 5.8186$ & $38.692 \pm 3.9566$ & $37.330 \pm 3.8783$ & 0.065 \\
\hline $\begin{array}{l}\text { A-N Perp distance (maxillary skeletal) } \\
(\mathrm{mm})\end{array}$ & $3.124 \pm 3.0054$ & $0.483 \pm 2.0335$ & $-0.049 \pm 2.6478$ & $-1.833 \pm 2.3368$ & $0.000^{* * *}$ \\
\hline Pog-N Perp distance (mand. skeletal) (mm) & $-6.850 \pm 5.5424$ & $-9.546 \pm 3.9840$ & $-12.374 \pm 5.0959$ & $-13.695 \pm 4.2233$ & $0.000 * * *$ \\
\hline S-N/Go-Me (\%) & $96.082 \pm 8.1939$ & $96.910 \pm 7.5442$ & $99.765 \pm 6.0968$ & $102.723 \pm 7.7084$ & $0.000 * * *$ \\
\hline \multicolumn{6}{|l|}{ Vertical relationship measurements } \\
\hline $\mathrm{SN}-\mathrm{MP}\left({ }^{\circ}\right)$ & $33.335 \pm 5.0289$ & $34.404 \pm 4.4918$ & $37.687 \pm 4.4394$ & $42.063 \pm 5.7939$ & $0.000 * * *$ \\
\hline $\mathrm{FMA}\left({ }^{\circ}\right)$ & $26.735 \pm 5.9613$ & $27.233 \pm 4.4354$ & $28.689 \pm 4.8483$ & $30.893 \pm 5.4483$ & $0.000^{* * * *}$ \\
\hline Anterior facial height (mm) & $102.541 \pm 4.8120$ & $104.632 \pm 8.2218$ & $106.538 \pm 8.5353$ & $106.607 \pm 8.0810$ & $0.036^{*}$ \\
\hline Upper anterior facial height, N-ANS (mm) & $46.356 \pm 2.6656$ & $47.567 \pm 3.4740$ & $48.765 \pm 4.5107$ & $48.218 \pm 3.4777$ & $0.008^{* *}$ \\
\hline Lower anterior facial height, ANS-Me (mm) & $55.203 \pm 3.4811$ & $55.807 \pm 5.5889$ & $56.037 \pm 4.9425$ & $56.392 \pm 5.6307$ & 0.737 \\
\hline Posterior facial height (S-Go) (mm) & $68.250 \pm 3.8592$ & $68.041 \pm 7.7363$ & $67.414 \pm 6.1875$ & $64.328 \pm 5.7124$ & $0.003^{* *}$ \\
\hline Facial height Index (\%) & $66.629 \pm 3.8770$ & $65.083 \pm 5.9671$ & $63.304 \pm 3.4535$ & $60.383 \pm 3.4987$ & $0.000^{* * *}$ \\
\hline \multicolumn{6}{|l|}{ Dental measurements } \\
\hline $\operatorname{IMPA}\left({ }^{\circ}\right)$ & $97.868 \pm 7.7346$ & $97.570 \pm 5.1673$ & $99.262 \pm 6.2497$ & $95.285 \pm 7.4341$ & $0.009^{* *}$ \\
\hline FMIA $\left({ }^{\circ}\right)$ & $55.385 \pm 7.2962$ & $55.203 \pm 5.8499$ & $52.048 \pm 5.9452$ & $53.813 \pm 6.1375$ & $0.001^{* *}$ \\
\hline U1-SN $\left(^{\circ}\right)$ & $108.209 \pm 9.9821$ & $109.213 \pm 8.0640$ & $104.566 \pm 8.3296$ & $102.717 \pm 10.5305$ & $0.000 * * *$ \\
\hline U1-L1 (interincisal angle) $\left(^{\circ}\right.$ ) & $120.585 \pm 14.0433$ & $118.812 \pm 9.1669$ & $118.478 \pm 10.8300$ & $119.937 \pm 13.7186$ & 0.727 \\
\hline $\mathrm{SN}-\mathrm{OP}\left({ }^{\circ}\right)$ & $18.800 \pm 3.9969$ & $19.726 \pm 3.9418$ & $22.013 \pm 3.6525$ & $24.667 \pm 3.6695$ & $0.000^{* * *}$ \\
\hline $\mathrm{MP}-\mathrm{OP}\left({ }^{\circ}\right)$ & $14.574 \pm 4.1280$ & $14.681 \pm 4.2908$ & $15.678 \pm 4.2563$ & $17.397 \pm 5.5670$ & $0.003^{* *}$ \\
\hline U6-PP (mm) & $16.506 \pm 1.8918$ & $16.162 \pm 2.4600$ & $16.208 \pm 2.3649$ & $16.197 \pm 2.5863$ & 0.912 \\
\hline
\end{tabular}

Contd... 


\begin{tabular}{lccccc} 
Contd... & \multicolumn{1}{l}{} \\
\hline Measurements & GI $(n=34)$ & GIV $(n=69)$ & GV $(n=133)$ & GVI $(n=60)$ & $p$ \\
\hline L6-MP $(\mathrm{mm})$ & $27.553 \pm 1.9274$ & $27.932 \pm 2.5256$ & $28.056 \pm 2.6646$ & $27.470 \pm 2.2129$ & 0.408 \\
Soft tissue measurements & & & & & \\
$\quad$ Nasolabial A $\left({ }^{\circ}\right)$ & $105.768 \pm 10.3170$ & $101.013 \pm 12.6922$ & $104.005 \pm 10.3897$ & $102.408 \pm 12.1932$ & 0.155 \\
FH-N'Pg' (S.T. facial angle) $\left({ }^{\circ}\right)$ & $85.918 \pm 3.3186$ & $84.400 \pm 2.2479$ & $82.903 \pm 2.8125$ & $82.088 \pm 2.3452$ & $0.000^{* * *}$ \\
N'-Sn-Pg'(facial convexity angle) $\left(^{\circ}\right)$ & $156.806 \pm 5.2693$ & $160.967 \pm 4.8152$ & $158.986 \pm 4.2796$ & $160.233 \pm 4.3701$ & $0.000^{* * *}$ \\
UL-EP $(\mathrm{mm})$ & $4.729 \pm 2.3498$ & $3.878 \pm 2.0479$ & $4.568 \pm 2.0878$ & $3.698 \pm 1.9396$ & $0.011^{*}$ \\
LL-EP $(\mathrm{mm})$ & $4.871 \pm 2.6719$ & $3.716 \pm 2.8761$ & $4.867 \pm 2.6372$ & $4.440 \pm 2.3261$ & $0.027^{*}$ \\
\hline
\end{tabular}

${ }^{*} p<0.05 ;{ }^{* *} p<0.01 ;{ }^{* * *} p<0.001$

Table 3: Demographic characteristics of different skeletal types

\begin{tabular}{lllllll}
\hline & GI & GII & GIII & GIV & GV & \\
\hline Sex & & & & & & \\
$\quad$ Female & 21 & 6 & 2 & 38 & 72 & 36 \\
$\quad$ Male & 13 & 4 & 2 & 31 & 21 & 24 \\
Proportion (\%) & 10.97 & 3.23 & 1.29 & 2.26 & 42.90 & 19.35 \\
Mean age (Mean \pm SD, year) & $9.46 \pm 1.01$ & $9.44 \pm 0.91$ & $9.27 \pm 0.49$ & $9.44 \pm 0.95$ & $9.24 \pm 1.06$ & $9.11 \pm 1.29$ \\
\hline
\end{tabular}

The values for angular, linear, and proportion cephalometric measurements in each group were evaluated and compared, which are mentioned below.

\section{Statistical Analysis}

The interobserver and intra-observer reliability of cephalometry were tested. For interobserver reliability, 20 randomly selected cephalograms were measured by two observers, and the intraclass correlation coefficient (ICC) was calculated. For intra-observer reliability, 20 randomly selected cephalograms were measured by each examiner for the first time. After a washout period of about 1 month, the same cephalograms were repeatedly measured by the observer, and ICC was also calculated. The examiners were not qualified to measure cephalograms unless ICC was greater than 0.8 .

Statistical analysis was performed with SPSS software (version 24.0, SPSS Inc, Chicago, IL, USA). The differences in the cephalometric measurements among the groups were evaluated through one-way analysis of variance (one-way ANOVA) when equal variances were assumed ( $p$ value $>0.05$ ), and the Duncan multiple comparisons were performed done at a significance level of $p$ value $=0.05$ if the difference was statistically significant in one-way ANOVA ( $p$ value $<0.05$ ).

\section{Results}

\section{Demographic Characteristics}

The 310 patients (175 females and 135 males) included in this study had a mean age of $9.24 \pm 1.09$ years. The most common sagittal skeletal type was group $\mathrm{V}$ (MxN and $\mathrm{MnR}, 42.90 \%)$, followed by group IV ( $\mathrm{MxN}$ and $\mathrm{MnN}, 22.26 \%$ ), and group III ( $\mathrm{MxN}$ and $\mathrm{MnR}$ ) was the least (1.29\%) (Table 3). The greatest ANB value was observed in group III (Fig. 2). As there were only 4 patients in group III and $\mathrm{X}$ patients in group II (MxP and MnP), these two groups were not included in the inferential statistics.

\section{Cranial Measurements}

Differences in sella angle and posterior cranial base length were statistically significant, whereas articular angle and anterior cranial base length showed no statistical differences among the 4 groups

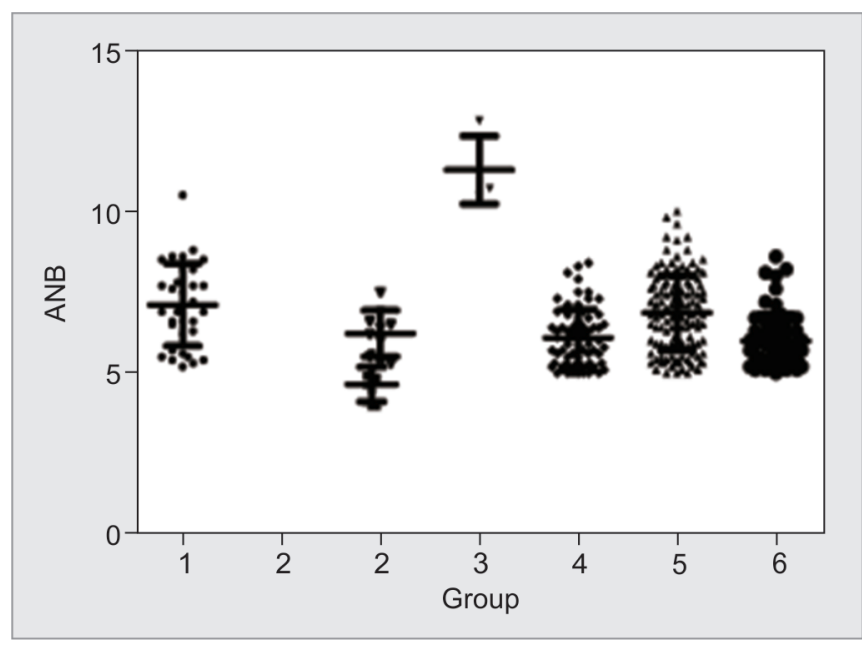

Fig. 2: Distribution of ANB values in types of skeletal class II malocclusions

(Table 2). Group VI exhibited the greatest sella angle and the shortest posterior cranial base length, while group I exhibited the least sella angle (Table 4).

\section{Maxillary, Mandibular, and Maxillomandibular Skeletal Measurements}

Differences in gonial angle, lower gonial angle, PP-MP, FH-NPo (facial angle), mandibular body length, A-N Perp Distance, Pog-N Perp Distance, and S-N/Go-Me were statistically significant, whereas upper gonial angle, $\mathrm{PP}-\mathrm{FH}$, and ramus height showed no statistical differences among the 4 groups (Table 2). Group VI exhibited the greatest gonial angle, lower gonial angle, PP-MP, S-N/Go-Me, and the least mandibular body length, A-N Perp Distance. Group I exhibited the greatest facial angle, A-N Perp Distance, and Pog-N Perp Distance.

\section{Vertical Relationship Measurements}

Differences in SN-MP, FMA, anterior facial height, upper anterior facial height(N-ANS), posterior facial height(S-Go), and Facial Height 
Table 4: Duncan multiple range test for group comparison

\begin{tabular}{|c|c|}
\hline Measurements & $\begin{array}{l}\text { Homogeneous subsets } \\
\text { with statistically significant } \\
\text { difference }(p<0.05)^{*}\end{array}$ \\
\hline $\mathrm{N}-\mathrm{S}-\operatorname{Ar}\left({ }^{\circ}\right)$ & $1<4<5<6$ \\
\hline $\mathrm{S}-\mathrm{Ar}(\mathrm{mm})$ & $6<(1,5,4)$ \\
\hline Gonial angle $\left(^{\circ}\right)$ & $(4,1,5)<6$ \\
\hline Lower gonial angle $\left(^{\circ}\right)$ & $(4,1,5)<6$ \\
\hline PP-MP $\left(^{\circ}\right)$ & $(1,4,5)<6$ \\
\hline FH-NPo (Facial angle) $\left(^{\circ}\right)$ & $(6,5)<4<1$ \\
\hline Mandibular body length (mm) & $6<(5,1,4)$ \\
\hline $\begin{array}{l}\text { A-N Perp distance (Maxillary skeletal) } \\
(\mathrm{mm})\end{array}$ & $6<(5,4)<1$ \\
\hline $\begin{array}{l}\text { Pog-N Perp distance (Mand. skeletal) } \\
(\mathrm{mm})\end{array}$ & $(6,5)<4<1$ \\
\hline S-N/Go-Me (\%) & $(1,4)<5<6$ \\
\hline SN-MP $\left({ }^{\circ}\right)$ & $1<4<(5,6)$ \\
\hline FMA $\left(^{\circ}\right)$ & $(1,4)<(4,5)<6$ \\
\hline Anterior facial height (mm) & $(1,4)<(4,5,6)$ \\
\hline $\begin{array}{l}\text { Upper anterior facial height, N-ANS } \\
(\mathrm{mm})\end{array}$ & $(1,4)<(4,6,5)$ \\
\hline Posterior facial height (S-Go) (mm) & $6<(5,4,1)$ \\
\hline Facial height index (\%) & $6<5<4<1$ \\
\hline IMPA $\left({ }^{\circ}\right)$ & $(6,4,1)<(4,1,5)$ \\
\hline FMIA $\left({ }^{\circ}\right)$ & $(5,6)<(6,4,1)$ \\
\hline U1-SN $\left(^{\circ}\right)$ & $(6,5)<(1,4)$ \\
\hline $\mathrm{SN}-\mathrm{OP}\left({ }^{\circ}\right)$ & $(1,4)<5<6$ \\
\hline MP-OP $\left(^{\circ}\right)$ & $(1,4,5)<6$ \\
\hline FH-N'Pg' (S.T. facial angle) $\left(^{\circ}\right)$ & $(6,5)<4<1$ \\
\hline $\mathrm{N}^{\prime}-\mathrm{Sn}-\mathrm{Pg}^{\prime}$ (Facial convexity angle) $\left(^{\circ}\right)$ & $1<(5,6)<(6,4)$ \\
\hline $\mathrm{UL}-\mathrm{EP}(\mathrm{mm})$ & $(6,4)<(4,5)<(5,1)$ \\
\hline LL-EP (mm) & $(4,6)<(6,5,1)$ \\
\hline
\end{tabular}

Index were statistically significant, whereas lower anterior facial height (ANS-Me) showed no statistical differences among the 4 groups (Table 2). Facial Height Index had the most effective ability to discriminate the differences among the 4 groups compared to other variables related to vertical relationship (Table 4). Group I exhibited the greatest posterior facial height, facial height index, and the least SN-MP, FMA, anterior facial height, and upper anterior facial height (Table 4).

\section{Dental Measurements}

Differences in IMPA, FMIA, U1-SN, SN-OP, and MP-OP were statistically significant, whereas Interincisal Angle, U6-PP, and L6-MP showed no statistical differences among the 4 groups (Table 2). Group VI exhibited the greatest SN-OP, MP-OP, and smaller IMPA than group V. Group V showed smaller FMIA and U1-SN than groups I and IV (Table 4).

\section{Soft Tissue Measurements}

Differences in FH-N'Pg' (S.T. Facial Angle), N'-Sn-Pg' (Facial convexity angle), UL-EP, and LL-EP were statistically significant, whereas nasolabial angle showed no statistical differences among the 4 groups (Table 2). Group I exhibited the greatest S.T. facial angle and the least facial convexity angle. Group V showed smaller FMIA and U1-SN than groups I and IV (Table 4). Group VI showed smaller

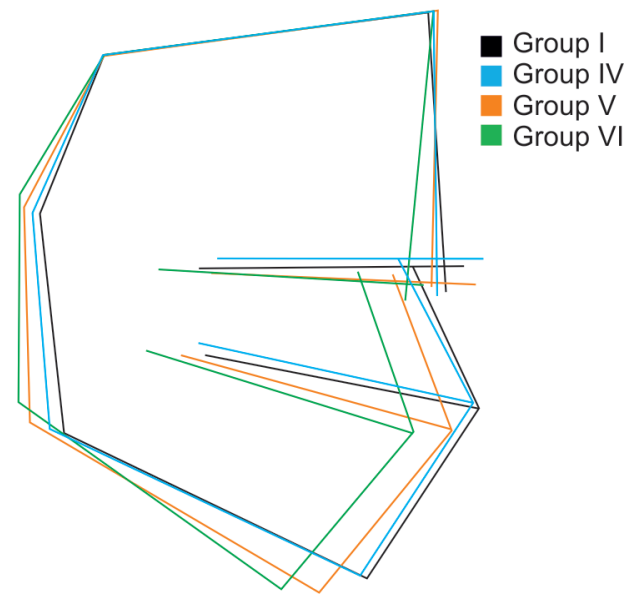

Fig. 3: Mean profilograms of group I (MxP and $M n N$, black line), group IV ( $\mathrm{MxN}$ and $\mathrm{MnN}$, blue line), group V ( $\mathrm{MxN}$ and $\mathrm{MnR}$, yellow line), and group VI (MxR and MnR, green line)

UL-EP than group V. Group V showed smaller UL-EP than group I. Group IV showed smaller LL-EP than groups V and I.

We infer that the most common etiology forming skeletal class II malocclusion in Chinese children was MnR, which was mainly caused by the small size and hyperdivergent growth direction of mandible.

\section{Discussion}

In this study, we described the proportion of different facial types in Chinese skeletal class II patients with mixed dentition and analyzed the differences in craniomaxillofacial characteristics. Patients with $\mathrm{MxP}$ and $\mathrm{MnP}$ (group II) and patients with MxP and MnR (group III) had a small proportion which was $3.23 \%$ and $1.29 \%$, respectively. In all, $62.26 \%$ of the patients exhibited MnR with either normal or retruded maxilla, suggesting a large portion of mandibular deficiency and clockwise rotation. There were statistical differences in 25 cephalometric measurements among groups I, IV, V and VI. Each facial type showed unique craniomaxillofacial characteristics to some extent.

Our study showed only $15.49 \%$ of the sample exhibited maxillary protrusion, which was quite different from several previous studies. ${ }^{18,19}$ The most possible reason might be the ethnic difference. The Caucasian population had relatively protrusive maxilla, ${ }^{20}$ and compared to Caucasian, Chinese had smaller mandible and steeper mandibular plane. ${ }^{21}$ The facial types of group I and group IV did not show excessive discrepancies in vertical measurement. The maxilla in group I showed excessive forward growth. Thus, for the treatment of group I, restricting the growth of maxilla with anchorage might be critical.

About three-fifth of the sample showed mandible retrusion. Compared to group IV, group V possessed greater clockwiserotated mandible (Fig. 3). And for group $\mathrm{VI}$, this trend was more obvious. Group VI exhibited the greatest PP-MP, FMA, SN-OP and MP-OP, which suggests the clockwise rotation might start from the palatal and get more obvious at the occlusal plane. Our findings are in agreement with Fushima et al. $^{22}$ who reported that steep cant of posterior occlusal plane was strongly correlated with small, retruded mandible with backward rotation.

It is interesting that around one-fifth of the sample exhibited MxR and MnR. And this type showed the biggest sella angle and 
shortest posterior cranial base. Louis ${ }^{23}$ revealed that patients with longer posterior cranial bases had more retruded mandibles. As the difference in sella angle was more remarkable, we could infer that maybe the shorter posterior cranial base in group VI was to compensate for the bigger sella angle. Besides, the size of mandible in group VI was the smallest, and in vertical measurements, group VI had the biggest SN-MP and FH-MP. Thus, if orthopedic treatment could alter the growth direction and amount of mandible, guiding it to grow counterclockwise would be critical. ${ }^{24}$ For severe retruded and small mandible, it might be better to wait for orthognathic surgery and not to intervene early. For the treatment strategy of mild to moderate $\mathrm{MxR}$ and $\mathrm{MnR}$, restricting the maxillary might need to be avoided, and in order to get a normal craniomaxillary relationship, promoting the growth of maxillary and creating enough space for mandible growth and counterclockwise rotation could be considered.

A remarkable advantage of this study is the large sample size. Compared to historic studies, more comprehensive cephalometric measurements were used to describe the features of different facial types from different aspects. We found that the main factor causing skeletal class II malocclusion in Chinese children with mixed dentition was $M n R$, which exhibited a relatively small size and clockwise-rotation tendency of mandible. Thus, the importance of FAs for Chinese class II children should be reconsidered thoroughly. There might be more need for length augmentation and growth direction change of mandible in Chinese children. Several studies reported the favorable effects of FAs in Mongoloid children and young adults. ${ }^{25-27}$ With more clinical trials in the future confirming the effects of FAs in Mongoloid population, especially Chinese, the application of FAs could be encouraged.

One major limitation of this study was that the relative jaw relationship was determined by ANB angle. The ANB angle is mostly used by clinicians, and it is directly related to the cranial base, which helps us to illustrate mechanisms. However, based on some studies, ANB angle did have some fallacies, ${ }^{28}$ as it might be influenced by sagittal position of point $\mathrm{N}$, length of anterior cranial base, maxillary rotation, and vertical distance between point $A$ and $B$ as well as point $N$ and $B$. In our study, the length of anterior cranial base showed no significant differences in each group. And we evaluated A-N Perp Distance, Pog-N Perp Distance according to McNamara analysis, ${ }^{29}$ which showed a similar trend with SNA and SNB. The error caused by ANB angle was relatively small.

\section{Conclusion}

This cross-sectional study showed that the most common etiology forming skeletal class II malocclusion in Chinese children was mandibular retrusion, which was mainly caused by the small size and hyperdivergent growth direction of the mandible. For the early orthodontic treatment of Chinese class II children with mixed dentition, orthodontists should emphasize mandibular length augmentation and growth direction change of mandible.

\section{References}

1. Proffit WR. Contemporary orthodontics 5th ed, United States: Mosby; 2014.

2. Buschang PH, Roldan SI, Tadlock LP. Guidelines for assessing the growth and development of orthodontic patients. Semin Orthod 2017;23(4):321-335. DOI: 10.1053/j.sodo.2017.07.001.

3. Zhao M, Luo S, Chen Y. Functional orthopaedics of dental and maxillofacial deformities. 1st ed., Beijing, China: Science and Technology Literature Publishing House; 2016.
4. Zymperdikas VF, Koretsi V, Papageorgiou SN, et al. Treatment effects of fixed functional appliances in patients with class II malocclusion: a systematic review and meta-analysis. Eur J Orthod 2015;38(2):113-126. DOI: $10.1093 /$ ejo/cjv034.

5. Koretsi V, Zymperdikas V, Papageorgiou S, et al. Treatment effects of removable functional appliances in patients with class II malocclusion: a systematic review and meta-analysis. Eur J Orthod 2015;37(4):418-434. DOI: 10.1093/ejo/cju071.

6. Perinetti G, Primožič J, Franchi L, et al. Treatment effects of removable functional appliances in Pre-pubertal and pubertal class II patients: a systematic review and meta-analysis of controlled studies. PLoS ONE 2015;10(10):e0141198. DOI: 10.1371/journal.pone.0141198.

7. Celikoglu M, Buyuk SK, Ekizer A, et al. Treatment effects of skeletally anchored Forsus FRD EZ and Herbst appliances: a retrospective clinical study. Angle Orthod 2016;86(2):306-314. DOI: 10.2319/040315225.1.

8. Kinzinger GSM, Lisson JA, Frye L, et al. A retrospective cephalometric investigation of two fixed functional orthodontic appliances in class II treatment: functional mandibular dvancer vs. Herbst appliance. Clin Oral Investig 2017;22(1):1-12. DOI: 10.1007/s00784-017-2111-5.

9. Graber LW, Vanarsdall RL, Vig KW, et al. Orthodontics-E-Book: current principles and techniques: . Elsevier Health Sciences; 2016.

10. Stupar I, Yetkiner E, Wiedemeier D, et al. Influence of lateral cephalometric radiographs on orthodontic treatment Planning of class II patients. Open Dent J 2018;12(1):296. DOI: 10.2174/1874210601812010296.

11. Rosenblum RE. Class II malocclusion: Mandibular retrusion or maxillary protrusion? Angle Orthod 1995;65(1):49-62. DOI: 10.1043/0003-3219(1995)0652.0.CO;2.

12. Pancherz H, Zieber K, Hoyer B. Cephalometric characteristics of class II division 1 and class II division 2 malocclusions: a comparative study in children. Angle Orthod 1997;67(2):111-120. DOI: 10.1043/00033219(1997)0672.3.CO;2.

13. OhE, Ahn SJ, Sonnesen L. Ethnic differences in craniofacial and upper spine morphology in children with skeletal class II malocclusion. Angle Orthod 2018;88(3):283-291. DOI: 10.2319/083017-584.1.

14. Joshi N, Hamdan AM, Fakhouri WD. Skeletal malocclusion: a developmental disorder with a life-long morbidity. J Clin Med Res 2014;6(6):399-408. DOI: 10.14740/jocmr1905w.

15. Li J.Craniomaxillofacial characteristics of adult skeletal class II patients and discriminant analysis of surgical and non-surgical treatment. Xi'an. China: The Fourth Military Medical University;; 2013.

16. Chen Y. Orthodontics foundation, technology and clinical. Beijing, China: People's Medical Publishing House; 2012. p. 783.

17. van VO, Bergé S, Swennen G, et al. Comparison of cephalometric radiographs obtained from cone-beam computed tomography scans and conventional radiographs. J Oral Maxillofac Surg 2009;67(1): 92-97. DOI: 10.1016/j.joms.2008.04.025.

18. Rothstein T, Yoon-Tarlie C. Dental and facial skeletal characteristics and growth of males and females with class II, division 1 malocclusion between the ages of 10 and 14 (revisited) - part I: Characteristics of size, form, and position. Am J Orthod Dentofacial Orthop 2000;117(3):320-332. DOI: 10.1016/s0889-5406(00)70237-x.

19. Moyers RE, Riolo ML, Guire KE, et al. Differential diagnosis of class II malocclusions: Part 1. Facial types associated with class II malocclusions. Am J Orthod 1980;78(5):477-494. DOI: 10.1016/00029416(80)90299-7.

20. De Castrillon FS, Baccetti T, Franchi L, et al. Lateral cephalometric standards of Germans with normal occlusion from 6 to 17 years of age. J Orofac Orthop 2013;74(3):236-256. DOI: 10.1007/s00056-0130140-5.

21. Yan G, Mcnamara JA, Sigler LM, et al. Comparison of craniofacial characteristics of typical chinese and caucasian young adults. Eur J Orthod 2011;33(2):205-211. DOI: 10.1093/ejo/cjq054.

22. Fushima K, Kitamura $\mathrm{Y}$, Mita $\mathrm{H}$, et al. Significance of the cant of the posterior occlusal plane in class II division 1 malocclusions. Eur J Orthod 1996;18(1):27-40. DOI: 10.1093/ejo/18.1.27. 
23. Andria LM, Leite LP, Prevatte TM, et al. Correlation of the cranial base angle and its components with other dental/skeletal variables and treatment time. Angle Orthod 2004;74(3):361-366. DOI: 10.1043/00033219(2004)0742.0.CO;2.

24. Haralabakis NB, Sifakakis IB. The effect of cervical headgear on patients with high or low mandibular plane angles and the "myth" of posterior mandibular rotation. Am J Orthod Dentofacial Orthop 2004;126(3):310-317. DOI: 10.1016/j.ajodo.2003.08.028.

25. Kim J-E, Mah S-J, Kim T-W, et al. Predictors of favorable soft tissue profile outcomes following class II twin-block treatment. Korean J Orthod 2018;48(1):11-22. DOI: 10.4041/kjod.2018.48.1.11.

26. Lei J, Yap AUJ, Liu MQ, et al. Condylar repair and regeneration in adolescents/young adults with early-stage degenerative temporomandibular joint disease: a randomised controlled study. $J$ Oral Rehabil 2019;46(8):704-714. DOI: 10.1111/joor.12805.

27. Du X, Hägg U, Rabie ABM. Effects of headgear Herbst and mandibular step-by-step advancement versus conventional Herbst appliance and maximal jumping of the mandible. Eur J Orthod 2002;24(2):167-174. DOI: 10.1093/ejo/24.2.167.

28. Del Santo M. Jr. Influence of occlusal plane inclination on ANB and wits assessments of anteroposterior jaw relationships. Am $J$ Orthod Dentofacial Orthop 2006;129(5):641-648. DOI: 10.1016/j. ajodo.2005.09.025.

29. McNamara JA,Jr. Components of class II malocclusion in children 8-10 years of age. Angle Orthod 1981;51(3):177-202. DOI: 10.1043/00033219(1981)0512.0.CO;2. 